\title{
Vacillating time: a metaphysics for time travel and Geachianism
}

\author{
Nikk Effingham ${ }^{1}$ (D)
}

Received: 17 August 2020 / Accepted: 1 March 2021 / Published online: 16 May 2021

(c) The Author(s) 2021

\begin{abstract}
'Past vacillators' believe that what was once the case may change over time. This has obvious applications to the possibility of changing the past via time travel. 'Future vacillators' believe that some things will happen and yet, later, will not. Further to issues in time travel, future vacillation has applications when it comes to 'Geachian' views about the open future. This paper argues that if you deny that the 'earlier than' and 'later than' relations are converses of one another then you can develop metaphysical systems underpinning the possibility of such vacillation.
\end{abstract}

Keywords Time Counterfactuals $\cdot$ Geachianism - Time travel $\cdot$ Ersatz presentism . Tensed time $\cdot$ Tenseless time $\cdot$ Open future

Standardly, we believe that what once was, will always have once been. For instance, the Battle of Hastings took place in $1066 \mathrm{AD}$ and, in the future, will always have taken place in 1066 AD. Similarly, if something is non-trivially true at some time in the future, it's standard to add that it will always be true at that time e.g. if today it's true that I'll die in 2077 AD, then it'll always be true that I die in 2077 AD. Using 'WAS ${ }_{n}$ ' and 'WILL ${ }_{n}$ ' as the tense-operators (respectively saying that the proposition they operate on was/will be the case $n$ years ago/from now), these two principles can be translated as:

$$
\begin{aligned}
& \text { FIXED PAST: WAS } \\
& n
\end{aligned}
$$

Nikk Effingham

nikk.effingham@gmail.com

1 University of Birmingham, Birmingham, UK 
Temporal vacillation is the view that at least one of those principles is false. Those who deny FIXED PAST are past vacillators. Those who deny FIXED FUTURE are future vacillators.

An obvious application of past vacillation is with regards to changing the past in time travel cases. For instance, currently Hitler is alive in 1930 AD but I might use a time machine to go back in time and murder him before he took over Germany. Past vacillation allows for that possibility. $\S 1$ details a tenseless version of past vacillation, whilst $\$ 2$ details a tensed version riffing off of presentism. I am not the first to discuss this model of time travel; in $\S 3$ I look at other discussions of past vacillation, focussing on the challenges past vacillation is thought to face. I explain how the theory I present overcomes those challenges.

Temporal vacillation isn't only relevant to time travel scenarios. 'Geachians' develop a theory of the open future which takes a denial of FIXED FUTURE as its starting point (Todd, 2011, 2016). §4 explains Geachianism and a corresponding theory of future vacillation. In this case, the tenseless version of the theory is too odd to be attractive and only the tensed version is sensible to endorse.

\section{Tenseless past vacillation}

\subsection{Vanilla tenseless theory}

This section details a tenseless metaphysical system allowing for past vacillation. Start with the 'vanilla' non-vacillating tenseless theory, as applied to a Newtonian spacetime. (Relativistic extensions of the theories in this paper will have to wait for another time.) Such a spacetime is composed of hyperplanes. The hyperplanes are composed of maximally spatially inter-related points, all of which are simultaneous with one another. Usually we would call such hyperplanes 'instants', but that term might become misleading later on when I talk about distinct hyperplanes in some sense 'existing at the same instant', so I will use the more neutral term 'hyperplanes ${ }_{\max }$ '

The vanilla tenseless theory then comprises three claims.

VANILLA PRIMITIVE: The three-place tenseless relation ' _ is earlier than _ by - years' is primitive. Represent it using ' $E$ ', where ' $h_{x} \bar{E}_{n} h_{y}$ ' represents that hyperplane $_{\max } h_{x}$ is $n$ years earlier than hyperplane ${ }_{\max } h_{y}$. The two-place 'earlier than' relation, $E$, is defined in terms of that primitive:

$$
h_{x} E h_{y}=_{\mathrm{df}} \text { for some positive number } m, h_{x} \dot{e}_{m} h_{y} \text {. }
$$

L/É CONVERSE: The '___is later than_ by _ years' relation (' $L$ ') is the converse of $\dot{E}$ (i.e. $\forall h_{x} \forall h_{y} \forall n \bar{h}_{x} \dot{E}_{n} h_{y} \leftrightarrow h_{y} \bar{L}_{n} h_{x}$ ). The 'later than' relation, $L$, can then be defined as: $h_{x} L h_{y}=_{\mathrm{df}}$ for some positive number $m, h_{x} \dot{L}_{m} h_{y}$. 
TENSELESS TRUTH CONDITIONS: The alethic status of tensed sentences is determined as follows:

(a) Utterances of the form ' $\mathrm{WAS}_{n}: \varphi$ ' are true $\leftrightarrow t$ and $t^{*}$ are hyperplanes ${ }_{\max }$ such that: (i) the utterance is exactly located at a part of $t$; (ii) $t^{*}$ is earlier than $t$ by $n$ years; (iii) $\varphi$ is true of $t^{*}$.

(b) Utterances of the form ' $\mathrm{WILL}_{n}: \varphi$ ' are true $\leftrightarrow t$ and $t^{*}$ are hyperplanes ${ }_{\max }$ such that: (i) the utterance is exactly located at a part of $t$; (ii) $t^{*}$ is later than $t$ by $n$ years; (iii) $\varphi$ is true of $t^{*}$.

(Present tensed sentences, e.g. of the form 'It is now the case that $\varphi$ ', are evaluated as being of the form ' $\mathrm{WAS}_{0}: \varphi$ '/'WILL $\mathrm{L}_{0}: \varphi$ ').

\subsection{Past vacillation tenseless theory}

With the vanilla theory in place, I can tweak it to allow for past vacillation. The key change is a denial of Ĺ/É CONVERSE (and that, rather than being inter-definable, $L$ and $E$ are distinct primitives). That's a controversial claim! But I don't dispute that past vacillation is revisionary, and it is in just this respect in which it finds that revision.

Nor is the revision so outlandish that the resulting metaphysical system is obviously impossible. Other principles about space and time have been thought to be intuitively true and then turned out to be up for revision and debate. The denial of Ĺ/É CONVERSE is just another example. Consider three other examples of such revisions. One: If something is to your right then it cannot also be to your left (which is false in appropriately curved spacetimes). Two: Space necessarily has three dimensions (which is false in, e.g., flatlands). Three: Space and time are separate dimensions (which is false given standard interpretations of relativity). Denying Ĺ/É CONVERSE might well be similar, and it's not obviously wrong-headed for this paper to consider the metaphysical ramifications of it being false.

To see how Ĺ/É CONVERSE'S denial allows for the past to vacillate, consider an example scenario. In 2019 AD, I time travel back to 1930 AD and kill Hitler. Since time can vacillate, in $2020 \mathrm{AD}$ the past changes such that Hitler was assassinated back in $1930 \mathrm{AD}$. The proposal of this paper is that activating the time machine causes a new set of hyperplanes $\max _{\max }$ to exist. See Fig. 1 (which marks out hyperplanes ${ }_{\max }$ from different years, such that $h_{n}$ is a hyperplane $\max _{\max }$ from the year $n$ AD). The hyperplanes ${ }_{\max }$ brought into existence by the time machine are $h_{1930^{\prime}}, h_{1980^{\prime}}, h_{2019^{\prime}}$ etc. And, just as what takes places at $h_{1930}$ causally depends on what takes place at $h_{1929}$, what takes place at $h_{1930}$, also partially depends on the events at $h_{1929}$-note that it's only partial dependence because my appearing and killing Hitler at $h_{1930^{\prime}}$ is a result of something taking place, not at $h_{1929}$, but at $h_{2019 \cdot}{ }^{1}$

\footnotetext{
${ }^{1}$ One worry is that $h_{1930}$ contains someone who looks like Hitler, but who isn't Hitler. Exactly this worry faces universe indexers (q.v.), whereby time travel takes us to another universe populated by people who only look like people from our past, rather than themselves being the people from our past. Elsewhere, I've argued that universe indexers can dissolve this problem by treating entities in the other universe as having fissioned from the original [2020: 82-84]. The same idea works here. Given vacillation, the contents of hyperplanes ${ }_{\max }$ fission. In 1929 AD Hitler has not fissioned; by $1930 \mathrm{AD}$, he has fissioned in two, with one Hitler occupying $h_{1930}$ and another occupying $h_{1930}$. Thanks to a referee for pressing me on this point.
} 
Fig. 1 Tenseless past Vacillation

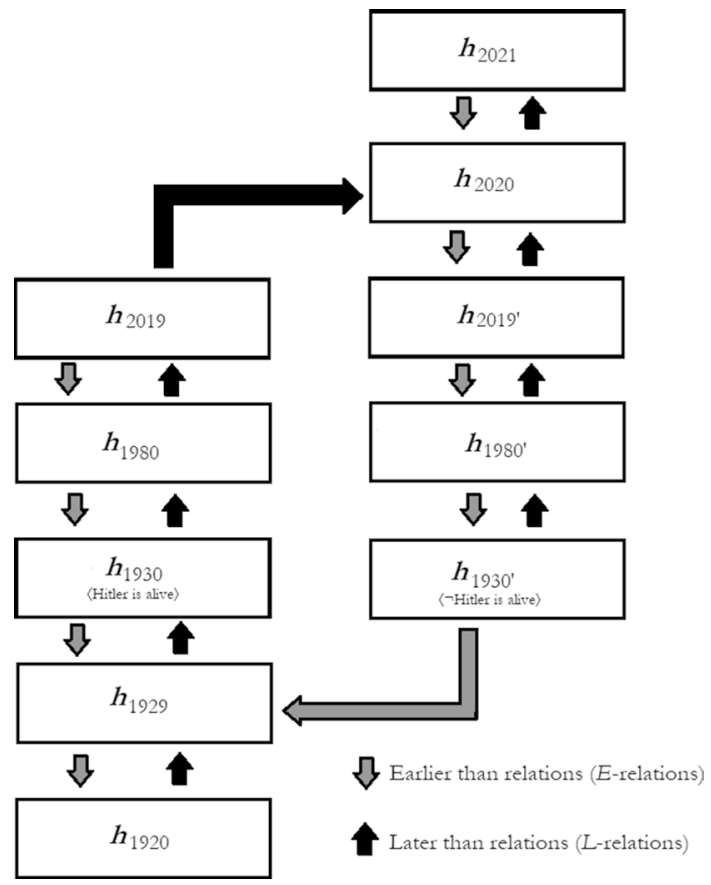

Time travelling also brings about idiosyncratic temporal relations between those hyperplanes $\max _{\max }$. The arrows mark out the tenseless relations: the darker arrow marks out $L$-relations and the lighter arrow the $E$-relations (where if $h_{n} E h_{m}$ then $h_{n} E_{m-n} h_{m}$, mutatis mutandis for $\left.L / L\right)$. The idiosyncrasy, possible only because ĹÉ CONVERSE is false, is that $h_{2020}$ is one year later than two hyperplanes max $_{\text {an }}$ (namely $h_{2019}$ and $h_{2019^{\prime}}$ ) whilst only a single hyperplane ${ }_{\max }$ is one year earlier than it (namely $h_{2019^{\prime}}$ ). Similarly, $h_{1929}$ is one year earlier than two hyperplanes ${ }_{\max }$ ( $h_{1930}$ and $h_{1930^{\prime}}$ ) whilst only a single hyperplane max $_{\text {is }}$ ise year later than it $\left(h_{1930}\right)$.

Given such a set-up, FIXED PAST would be false. Consider the following sentence:

$s_{h}: 50$ years ago, Hitler was alive but in 40 years time he will be dead back then.

Clearly, $s_{h}$ can only be true if FIXED PAST is false and the past vacillates. If uttered in 1980, at hyperplane $\max _{1980}$, it is true (and so FIXED PAST is false). To demonstrate this, note that sentence $s_{h}$ comprises two conjuncts:

$\wedge_{1}:$ WAS $_{50}$ Hitler is alive

$\wedge_{2}:$ WILL $_{40}$ WAS $_{90} \neg$ Hitler is alive

Given TENSELESS TRUTH CONDITIONS, $\wedge_{1}$ is true iff it's true of the hyperplane max $_{\text {fifty }}$ years earlier that Hitler is alive i.e. iff it's true of $h_{1930}$ that Hitler is alive. And that's the case! Thus $\wedge_{1}$ is true. Similarly, $\wedge_{2}$ is true iff, at the hyperplane ${ }_{\max }$ forty years 
Fig. 2 Universe indexing

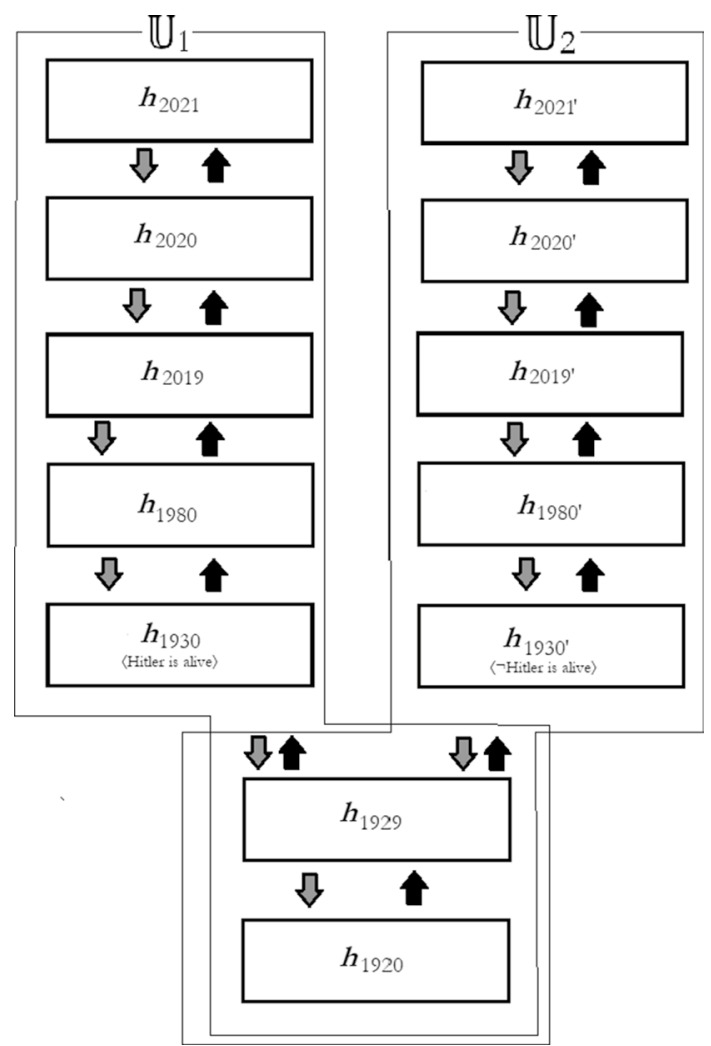

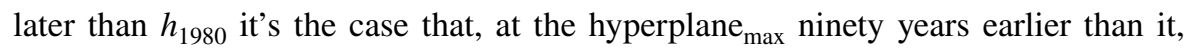
Hitler isn't alive. And that's also true! The hyperplane ${ }_{\max }$ forty years later than $h_{1980}$

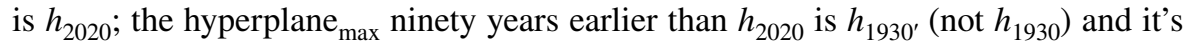
true of $h_{1930^{\prime}}$ that Hitler is dead. Thus, $\wedge_{2}$ is true. Since both conjuncts are true, $s_{h}$ is true when uttered at $h_{1980}$ i.e. the past vacillates.

\subsection{Comparison to similar views}

Other theories allowing for a changeable past are not entirely dissimilar to that just presented. One worry would therefore be that, rather than being original, my theory is only a variation on existing theories. This sub-section compares my theory to those existing theories, showing that they differ over some substantive matters and, thus, are different theories.

Start with 'universe indexed' worlds. When I travel in time, I leave my original universe, $\mathbb{U}_{1}$, arriving at another universe, $\mathbb{U}_{2}$. (See Effingham (2020: 73-75, 79-84) for full discussion of such theories.) This is depicted in Fig. 2 (which you can compare with Fig. 1). 
In some respects the theories are similar. In both, hyperplanes $\max _{\max }$ exist. Vis-àvis their ontologies, the only difference is that the universe indexer includes more hyperplanes $s_{\max }$ because $\mathbb{U}_{1}$ 'continues' after the time traveller leaves $\mathbb{U}_{1}$ such that everyone left behind by the time traveller continues to exist. In Fig. 1's world of past vacillation, on the other hand, the universe 'ends', being 'replaced' by one at which Hitler was assassinated in 1930.

However, the theories are dissimilar in other, more important, ways. Consider how universe indexers evaluate $s_{h}$. Whichever universe $s_{h}$ is uttered at, at least one of $\wedge_{1}$ and $\wedge_{2}$ must be false. Uttered at $\mathbb{U}_{1}$ (i.e. at $h_{1980}$ ), $\wedge_{2}$ is false: at $h_{1980}, 40$ years later is $h_{2020}$, from the perspective of which it is $h_{1930}$, not $h_{1930^{\prime}}$, that is 90 years earlier; since Hitler is alive at $h_{1930}, \wedge_{2}$ is false. Uttered at $\mathbb{U}_{2}$ (i.e. at $h_{1980^{\prime}}$ ), $\wedge_{1}$ is false: 50 years earlier than $h_{1980^{\prime}}$ is $h_{1930^{\prime}}$ and, at $h_{1930^{\prime}}$, Hitler is dead (having been assassinated by a time traveller). Therefore, whichever universe $s_{h}$ is uttered at, it's false given universe indexing. Since past vacillation theory and universe indexing differ over $s_{h}$ 's truth, the theories must be different.

Next, consider a theory of hypertemporal time travel (Goddu, 2003; van Inwagen, 2010; see also Effingham, 2020: 76-81, 84-90). Hypertemporal theorists introduce an extra dimension of time and, with it, extra tense operators, $\mathrm{HWAS}_{n}$ and HWILL ${ }_{n}$. Consider van Inwagen's theory, according to which time is a growing block that evolves at the rate of one second per hypersecond. When I time travel from 2020 to 1930, the edge of the growing block recedes, wiping out ninety years' worth of existential growth. Hypertime, though, continues onwards-whilst the present moment is now 1930, and last year is 1929, from the God's eye 'hypertemporal view' the present moment is nevertheless still hyperlater than my activation of the time machine in 2020 (and, further, the year hyperearlier than it is 2020, not 1929).

Hypertemporal theory is again different from past vacillation since $s_{h}$ is false given hypertemporal time travel, at least if $s_{h}$ is interpreted as being the conjunction of $\wedge_{1}$ and $\wedge_{2}{ }^{2}$ Imagine 'the first time' it's 1980. At that point, $\wedge_{1}$ is true (since Hitler is alive in 1930). $\wedge_{2}$ is not true, however. $\wedge_{2}$ says what the world will be like in 40 years' time and there won't be a 40 years' time, since I will activate my time machine and destroy reality before it grows that far. When 1980 'comes around again', $\wedge_{2}$ is true, but this time $\wedge_{1}$ is false because, when 1980 happens for the second time, Hitler died by my hands in 1930. So there's no time, hyper or otherwise, at which $s_{h}$ can be uttered and be true. Again, past vacillation theory and the hypertemporal theory disagree and thus must be different theories.

\footnotetext{
${ }^{2}$ The hypertemporal theorist could say $s_{h}$ was true if they gave an alternative interpretation of $s_{h}$, e.g.: WAS $_{50}$ : Hitler is alive HWILL $_{40}$ : WAS 90 : $\neg$ Hitler is alive.

But that's irrelevant to the matter at hand. What's relevant is that there's some proposition-in this case, the conjunction of $\wedge_{1}$ and $\wedge_{2}$-which the past vacillator and the hypertemporal indexer would disagree over. That's enough to show that their theories are distinct.
} 


\section{Tensed past vacillation}

\subsection{Presentist past vacillation theory}

The tenseless version of past vacillation theory took vanilla tenseless theory as a 'baseline' theory and then tweaked it. The tensed version does similarly. For convenience, I will take ersatz presentism (Bourne, 2006) as the baseline and then tweak that theory. Alternative versions, with different baselines (e.g. moving spotlight theory, growing block theory, fragmentalism etc.), could surely be developed; I leave investigation of those theories to the interested reader.

There's a short and a long version of how to develop a presentist past vacillation theory.

Short version. Those familiar with ersatz presentism already know that times are replaced by ersatz times. Similarly, tenseless relations (i.e. $\dot{E}$ and $\dot{L}$-relations) are replaced by ersatz equivalents (call them $E_{\varepsilon}$ and $\dot{L}_{\varepsilon}$-relations). Simply take tenseless past vacillation theory and carry out the relevant replacements: swap hyperplanes $\max _{\max }$ for ersatz substitutes, 'ersatzplanes'; swap $E^{\prime}$ and $L^{\prime}$-relations for ersatz $E_{\varepsilon}$ and $L_{\varepsilon^{-}}^{-}$ relations; deny that the converse of $E_{\varepsilon}$ is $L_{\varepsilon}$. Everything then functions the same as with the tenseless version of past vacillation theory.

For those less acquainted with ersatz presentism, the rest of $\$ 2.1$ presents the 'long version', the bulk of which consists in first explaining the details of vanilla ersatz presentism.

The vanilla ersatz presentist denies that there are non-present instants, replacing them with ersatz instants. Take ersatz instants to be propositions (Bourne, 2006; Markosian, 2004: 76). An ersatz instant of an instant $t$ is the conjunction of every 'intrinsic proposition' that would be true were $t$ present. Roughly, an 'intrinsic proposition' is any proposition which, were it true at some time, would be true in virtue only of things going on at that time. For example, for some instant in $1066 \mathrm{AD}$, the following would be true were it present:

〈The Battle of Hastings is taking place〉

〈Lý Thánh Tông is the Emperor of Đại Việt〉

〈The Duke of Normandy has the abstracted property of being such that the scholar Al-Qadi Abu Ya' la was once alive

The former two exclusively concern things presently occurring; they are intrinsic propositions. The third proposition concerns something going on at another time; it is not an intrinsic proposition. The former two (and not the third) therefore feature as conjuncts in the ersatz instant corresponding to that instant from 1066 AD.

Being abstract propositions, not concrete things, ersatz instants cannot be earlier than or later than one another. Instead, they stand in an ersatz equivalent to

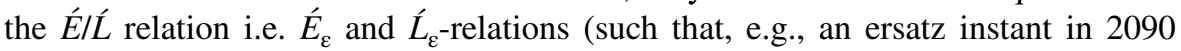
is 1024 years later $_{\varepsilon}$ than some ersatz instant in 1066). Finally, the presentist says that one ersatz instant is special, namely the present moment. It is special because, unlike the other propositions, it's true. 
This completes the exposition of a simple version of ersatz presentism. A fully developed theory would be more complicated e.g. adding in extra machinery to deal with qualitatively identical times (Bourne 2006: 66-68). This simple version will suffice for the purposes of this paper.

We must now tweak ersatz presentism to be an ersatz emulation of tenseless past vacillation theory. The tenseless theory focussed less on instants and more on hyperplanes $_{\max }$. Similarly, we should shift our focus from ersatz instants to ersatz equivalents of hyperplanes ${ }_{\max }$-call them 'ersatzplanes'. An ersatzplane is that proposition which has, as conjuncts, all and only those intrinsic propositions which the tenseless past vacillator says are true of the corresponding hyperplane $\max _{\operatorname{mos}}$. Those ersatzplanes are then related by $E_{\varepsilon}$ - and $L_{\varepsilon}$-relations (which, recall, are not the converse of one another). One ersatzplane is special--the present ersatzplane-in so far as it's true.

Next: If we think time is tenseless, there are no tensed propositions. ${ }^{3}$ That's why tenseless theorists focus on the truth of sentences in TENSELESS TRUTH CONDITIONS, rather than propositions. Given time is tensed, tensed propositions (rather than sentences) should instead be our focus. Thus, instead of TENSELESS TRUTH CONDITIONS, the ersatz presentist should accept:

TENSED TRUTH CONDITIONS:

Propositions of form $\left\langle\mathrm{WAS}_{n}: \varphi\right\rangle$ are true $\leftrightarrow \varepsilon_{t}$ and $\varepsilon_{t^{*}}$ are ersatzplanes such that: (i) $\varepsilon_{t} E_{\varepsilon n^{\prime}} \varepsilon_{t^{*}}$; (ii) $\varepsilon_{t^{*}}$ is present (i.e. it's true); (iii) $\varphi$ is a conjunct of (or entailed by) $\varepsilon_{t}$.

Propositions of form $\left\langle\mathrm{WILL}_{n}: \varphi\right\rangle$ are true $\leftrightarrow \varepsilon_{t}$ and $\varepsilon_{t^{*}}$ are ersatzplanes such that: (i) $\varepsilon_{t} \hat{L}_{\varepsilon n} \varepsilon_{t^{*}}$; (ii) $\varepsilon_{t^{*}}$ is present (i.e. it's true); (iii) $\varphi$ is a conjunct of (or entailed by) $\varepsilon_{t}$.

(Present tensed propositions, e.g. of the form $\langle$ It is now the case that $\varphi\rangle$ are evaluated as being of the form $\left\langle\mathrm{WAS}_{0}: \varphi\right\rangle$ or $\left\langle\mathrm{WILL}_{0}: \varphi\right\rangle$.)

That completes the exposition of tensed past vacillation theory.

\subsection{Yes, but what really happened?}

Tensed past vacillation theory has some interesting features. The tenseless theorist's hyperplanes $_{\max }$ are concrete existents inhabited by concrete entities. Thus, on the tenseless model, when time travel changes the past, the 'new past' occurs/happens/ exists to whatever extent the 'old past' occurred/happened/existed-the old past and new past have the same metaphysical status. But presumably this isn't the case for the tensed theorist. Imagine a God's eye view of the time travel story. God watches 1930. Hitler is alive and well. God watches all the events after 1930 which lead up to me getting into a time machine in 2019. God watches me activate the time machine and vanish... and then? Presumably, God sees the present moment suddenly shift and change to be how the world would be if only Hitler had been assassinated in

\footnotetext{
3 One referee worried that even given tenseless theory there may be tensed propositions. In that case tensed propositions would nevertheless fail to be true simpliciter and I can revise my claim here to merely be about the truth simpliciter conditions of propositions, rather than their truth conditions.
} 
Fig. 3 Tensed past vacillation

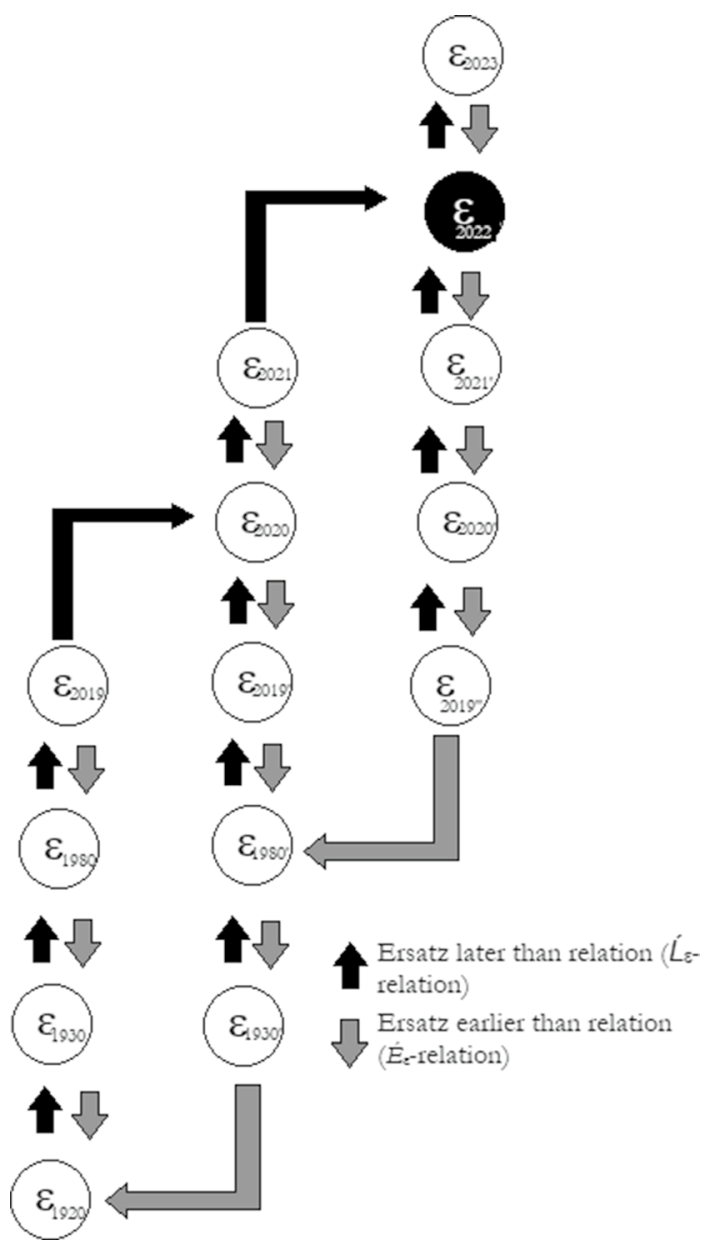

1930. Crucially, God doesn't witness me killing Hitler in 1930, nor any of the events of the 'new past' leading up to 2020. Whilst God notes that, according to the ersatzplanes which are now earlier $_{\varepsilon}$ than the present ersatzplane, I once did certain things (e.g. according to $\varepsilon_{1930^{\prime}}$ I killed Hitler), God himself never sees those things happen. In some sense, whilst those events happened, they never really happened.

In light of this metaphor, two questions arise. First: How can the tensed past vacillator express that things happen without really happening? Second: Is it a problem that a time traveller can make changes to the past, but that those changes never really happened?

To express the difference between what happened and what really happened, use a new operator, $\mathbf{W A S}_{n}$, to operate on propositions that really happened. For example:

$\mathbf{W A S}_{1}$ : event $e$ occurred.

says that $e$ really happened a year ago. 
The tensed past vacillator needn't treat the $\mathbf{W A S}_{n}$ operator as an extra piece of ideology, since their ersatzplane structure is already rich enough to analyse it. Start by defining:

Erstazplanes $\varepsilon_{x}, \varepsilon_{y} \ldots$ are coetaneous $=_{\mathrm{df}}$ there is some ersatzplane, $\varepsilon_{\alpha}$, and some number, $m$, such that $\varepsilon_{\alpha}$ is $m$ later than each of $\varepsilon_{x}, \varepsilon_{y} \ldots$

More informally, coetaneous ersatzplanes are those ersatzplanes that are the 'same instant' as one another but which belong to 'different timelines'. See Fig. 3, which depicts the story of me going back to kill Hitler in 2019, as well as another time traveller from 2021 also returning back to 2019. Dots represent the different ersatzplanes; the black dot represents the present (i.e. true) ersatzplane. Ersatzplanes $\varepsilon_{2019}, \varepsilon_{2019}$, and $\varepsilon_{2019 \text { " }}$ are each 'different versions' of some instant from 2019; they are (given the definition) coetaneous with one another (and themselves).

For any collection of coetaneous ersatzplanes, exactly one will be earlier than the present ersatzplane. For instance, in Fig. 3 only $\varepsilon_{2019^{\prime \prime}}$ is earlier than the present moment (i.e. earlier than $\varepsilon_{2022}$ ). The other coetaneous ersatzplanes (i.e. $\varepsilon_{2019}$ and $\varepsilon_{2019^{\prime}}$ ) belong to an 'outdated past' relative to the present moment. We can capture that by saying:

Ersatzplane $\varepsilon_{x}$ is in an outdated past relative to erastzplane $\varepsilon_{y}={ }_{\mathrm{df}}$ (i) $\varepsilon_{x}$ isn't earlier than $\varepsilon_{y}$; (ii) there is some ersatzplane $\varepsilon_{w}$ which is earlier than $\varepsilon_{y}$; (iii) $\varepsilon_{x}$ and $\varepsilon_{w}$ are coetaneous; (iv) there's no eratzplane, $\varepsilon_{z}$, which is: (a) later than $\varepsilon_{y}$ such that (b) $\varepsilon_{x}$ is earlier than $\varepsilon_{z}$.

We can now pick out which ersatzplane 'really happened'. In Fig. 3, what really happened was what happened at all the ersatzplanes depicted on the furthest left (e.g. $\varepsilon_{1920}, \varepsilon_{1930}, \varepsilon_{1980}, \varepsilon_{2019}, \varepsilon_{2020}, \varepsilon_{2021}, \varepsilon_{2022}$ etc. and $n o t \varepsilon_{1930^{\prime}}, \varepsilon_{1980^{\prime}}, \varepsilon_{2019^{\prime}}, \varepsilon_{2019^{\prime}}$ etc.). We can capture that by saying:

Ersatzplane $\varepsilon_{x}$ really happened $=_{\mathrm{df}} \varepsilon_{x}$ is coetaneous with a distinct earlier ersatzplane; and either:

(a) $\varepsilon_{x}$ isn't in the outdated past relative to any ersatzplane; or

(b) $\varepsilon_{x}$ is in the outdated past relative to some ersatzplane and no ersatzplane coetaneous with $\varepsilon_{x}$ is in the outdated past relative to $\varepsilon_{x}$.

We can then analyse the $\mathbf{W A S}_{n}$ operator:

$\mathbf{W A S}_{n}: \varphi={ }_{\mathrm{df}}$ Either:

(i) there is an ersatzplane, $\varepsilon_{x}$, such that: (a) $\varphi$ is entailed by $\varepsilon_{x}$; (b) $\varepsilon_{x}$ really happened; and (c) $\varepsilon_{x}$ is coetaneous with an ersatzplane $n$ units earlier than the present ersatzplane; 
or

(ii) $n=0$ and $\varphi$ is presently true.

(Whilst such distinctions are less useful for tenseless theorists, note that they can likewise define similar terms, e.g. 'coetaneous hyperplanes ${ }_{\max }$ ' and 'really happened' talk, by simply swapping the relevant pieces of terminology for their tenseless analogues.)

So the presentist can express the situation without having to introduce any weird ideology. It can all be cashed out in terms of the ersatzplane structure which they already believe in.

The second question was whether there's something problematic about there being things which happened but never really happened. For instance, in Fig. 3 it's presently the case that 92 years ago, Hitler was killed by someone who stepped out of a time machine i.e. $\left\langle\mathrm{WAS}_{92}\right.$ : Hitler was assassinated $\rangle$ is true. But this never really happened i.e. $\left\langle\mathbf{W A S} \mathbf{S}_{92}\right.$ : $\neg$ Hitler was assassinated $\rangle$ is true. I can see two causes for concern as to why this situation would be a problem.

The first cause for concern would be that it's contradictory to say that Hitler was assassinated even though that never really happened. In natural language, the word 'really' - when used as an operator-is redundant e.g. 'Bob is happy' and 'Really, Bob is happy' assert the same proposition. Whilst 'really' may do important linguistic work (e.g. drawing my conversational partner's attention to the importance of Bob's happiness), the operator contributes nothing to the sentence's content. Understood like this, to say that Hitler was assassinated but that it never really happened would be a contradiction.

But 'really' in 'really happened' isn't playing the same role as 'really' plays in 'Really, Bob is happy' since it's explicit that the $\mathbf{W A S}_{n}$ operator is different from the $\mathrm{WAS}_{n}$ operator. The $\mathbf{W A S}_{n}$ operator instead functions more like Fine's 'In reality' operator (Fine, 2001). Fine uses that operator to make sense of antirealist theories, such that anti-realists can say (in one sense) that something is the case whilst (in another sense) it isn't the case. For instance, an anti-realist about morality might want to say that killings babies is wrong but yet that there are no moral facts (and, thus, it isn't the case that killing babies is wrong). Fine's operator solves this, for we can say that whilst there are moral facts, anti-realism consists in the denial that in reality there are moral facts. For Fine, propositions of the form $\langle\varphi \wedge$ In Reality: $\neg \varphi\rangle$ are non-contradictory. The presentist's $\mathbf{W A S}_{n}$ operator is more similar to Fine's 'In reality' operator in that respect, and is unlike the natural language 'really' operator. All that said, $\left\langle\mathrm{WAS}_{92}\right.$ : Hitler was assassinated $\wedge \mathbf{W A S}_{92}: \neg$ Hitler was assassinated $\rangle$ won't be contradictory.

The second cause for concern is that this distinction between happening and really happening makes time travel somehow purposeless. Consider three examples. Example one: I time travel, kill Hitler, and then come back to the present. I remember being in the past and engaging in heroic escapades in order to return to the present. But in a very real sense, I'm wrong and none of that really happened. My adventures are a form of delusion! Example two: Given past vacillation, even if I avert World War II, it's not clear why this would be a good thing. The millions who suffered in that war, still really suffered. Moreover, whilst they now once led happier 
war-free lives, they never really led those happier war-free lives. Example three: I retire to 65 million $\mathrm{BC}$ to spend the remainder of my life dinosaur hunting. Given this tensed model, that seems crazy! If I did this, I'd never really have any extra mental states-my past-bound retirement would be a form of suicide.

Underscore these examples by noting why the same worries don't apply to tenseless past vacillation. On that model, if I kill Hitler, there are concrete hyperplanes $\max _{\max }$ at which I do have adventures in the past. And whilst I can do nothing about there remaining concrete hyperplanes $\max _{\max }$ at which millions suffer because of World War II, my killing Hitler nevertheless makes it the case that there are concrete hyperplanes $_{\max }$ where they do not suffer. And if I retire to the past, there'll be concrete hyperplanes $_{\max }$ at which my retirement plays out, just as real and solid as if I had stayed in the present. All of this is quite unlike what happens given the tensed version of past vacillation.

But this worry about purposelessness has nothing to do with past vacillation and everything to do with presentism. Whilst presentists can allow for the possibility of time travel (Keller \& Nelson, 2001) they should nevertheless expect that time travel is purposeless in this respect. According to the presentist, the past is unreal; truth according to the past is more like truth according to a novel than it is truth according to reality. Changing the past is therefore more like rewriting a novel than reworking reality. If I want to retire, I'd better make sure I presently retire, rather than travelling back in time; to use a time machine to have a good retirement is only as good as writing a novel according to which I had a good retirement. Which is to say, not that good at all! Similarly for averting World War II or my escapades assassinating Hitler. Presentism is the cause of the worry about purposelessness, not past vacillation and not the 'happened/really happened' distinction; purposelessness is only a problem for presentist past vacillation theory in that it's a problem for any sort of presentist time travel. ${ }^{4}$ Thus, presentist past vacillation theory is at least as plausible as theories of presentist time travel in general. ${ }^{5}$

\section{Challenges to past vacillation}

I am not the only one to have discussed past vacillation. Some discussions of past vacillation treat it as something to be avoided. Tallant and Ingram (2012; see also Tallant, 2018: 130-32) suggest that Cameron's theory $(2011$; 2013) allows for past vacillation, with all parties to the debate agreeing that this would be a bad thing. And Skow (2015: 56-61) argues that a tensed theory should allow for metaphysically impossible claims about past vacillation to at least be logically consistent. Whilst those discussions are hostile to past vacillation, it's not hard to imagine someone

\footnotetext{
${ }^{4} \mathrm{My}$ argument here is similar to others in the literature; see, e.g., Markosian (2020: 158-60). Hales (2010, 2011) also argues that presentism is a form of suicide, although Hales instead draws from this that presentism and time travel are incompatible.

5 Presentist time travel isn't entirely purposeless, of course. For example, if my best friend died last week, I could restore them to life-really, presently restore them!-by travelling back a week and preventing their death.
} 
'ponensing their tollens' and instead drawing the lesson that those metaphysical views are not only plausible, but in fact $d o$ lead to past vacillation being possible.

Other discussions are far less hostile. For instance, I believe the correct reading of Meiland is that he is a past vacillator, specifically a tenseless vacillator (Meiland, 1974: 166). That reading gels with what he says about his theory following from the understanding of time we already have, whereby the past can change over time in the same way that any other regular continuant can change over time (Meiland, 1974: 160). More clear-cut defences of the theory come from Goff (2010) and Wasserman (2018: 103-6). I will not examine the metaphysical systems they suggest, instead being interested only in the challenges that they see past vacillation theory facing (challenges which, in Wasserman's case, he does not think can be overcome). This section introduces those challenges and my solutions to them (\$3.1-3.2). I end by discussing how Wasserman's challenge still goes on to rule out an interesting variant of past vacillation theory $(\S 3.3)$.

\subsection{Goff's Challenges to past vacillation}

Goff thinks past vacillation theory must overcome the following challenge. In a world of past vacillation, after I assassinate Hitler in 1930 there must nevertheless be some sense in which Hitler 'used to be alive' in 1930. It's easy to see why Goff thinks this is a problem. Imagine a metaphysically possible world at which an assassin appears ex nihilo in $1930 \mathrm{AD}$, incorrectly believing themselves to be a time traveller from the future. They then kill Hitler. What would distinguish that world from the past vacillation world? Something must!

The answer is straightforward on my theory. In the case of the tenseless theorist, Hitler is alive at $h_{1930}$ and dead at $h_{1930^{\prime}}$. The existence of hyperplanes $\max$ like $h_{1930}$ is what makes it true that the past vacillator's world is different from the ex nihilo world. And the hyperplanes $\max _{\max }$, their relations, and their contents, are jointly what make it true that 'in some sense' Hitler was once alive in 1930 AD. Indeed, when we say 'in some sense', the past vacillator can interpret that as being the claim that it 'really happened' that Hitler was once alive in 1930 AD. So, in 2020 AD, it's true that, whilst it happened that Hitler was killed in 1930, he wasn't really. By sourcing the truthmakers in the hyperplanar ${ }_{\max }$ structure, we get what we need. (The tensed theorist can of course do likewise, swapping out hyperplanes ${ }_{\max }$ for ersatzplanes, $E$-/L-relations for $E_{\varepsilon}-/ L_{\varepsilon}$-relations, and so on.)

\subsection{Wasserman's challenge to past vacillation}

Wasserman's challenge is one of explanation. If I leave 2019 in my time machine and kill Hitler in 1930, come 2020 Hitler will be dead. But what explains the change? Why does Hitler go from being dead to being alive? The obvious explanation is that I clambered into a time machine, armed with a gun and a map to Hitler's house, in 2019. But if, in 1930, it was true that, in 2019, I was going to do that, why did we have to wait until 2020 for what was true in 1930 to change? Why does the 
event of me using the time machine only explain it now rather than also explaining it then?

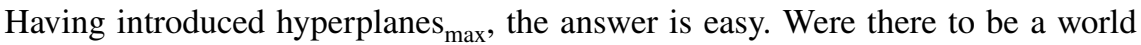
(like that depicted in Fig. 1) with a structure of hyperplanes ${ }_{\max }$, threaded by E-/Lrelations, then the past would vacillate such that, only come 2020, would Hitler be dead in 1930. Of course, that just shifts the burden and must go onto ask: Why is the

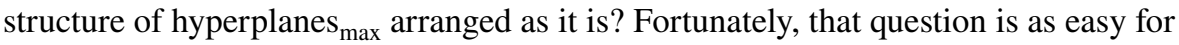
the past vacillator to answer as it is for the universe indexer to answer. $\$ 1.3$ 's Fig. 2 depicted the structure of hyperplanes max $_{\text {that }}$ there would be were I to go back to kill Hitler given universe indexing. In it, there are two universes, $\mathbb{U}_{1}$ and $\mathbb{U}_{2}$. I leave a 2019 hyperplane $_{\max }$ in $\mathbb{U}_{1}$ and travel to a 1930 hyperplane $_{\max }$ in $\mathbb{U}_{2}$, at which I kill Hitler. Assuming that time travel is what brings that second universe into existence, it seems satisfactory to explain those hyperplanes max $_{\text {existing (and being as they are) }}$ by saying that I time travelled back to 1930. Similarly, it seems a good explanation to say that Hitler dies at $h_{1930^{\prime}}\left(\right.$ in $\left.\mathbb{U}_{2}\right)$ because I clambered into a time machine with murder on my mind at $h_{2019}\left(\right.$ in $\left.\mathbb{U}_{1}\right)$. In short, the universe indexer's hyperplanes ${ }_{\max }$ have the arrangement (and qualities) that they do because of my time travelling back to $1930 \mathrm{AD}$ at $h_{2019}$.

The past vacillator's explanation is similar. Whilst the past vacillator believes in a slightly different collection of hyperplanes ${ }_{\max }$ (standing in different relations), their explanation is effectively the same. The coetaneous hyperplanes $\max _{\max }$ (e.g. Figure 1's $h_{1930^{\prime}}, h_{1980^{\prime}}, h_{2019^{\prime}}$ etc.) exist (and stand in the relevant $E$-/L-relations) because I time travel back to kill Hitler i.e. because I activate my time machine at $h_{2019}$. Since this

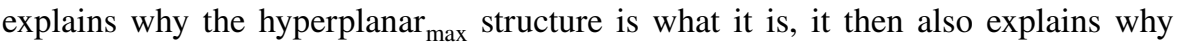
we must wait until 2020 AD for Hitler to die in 1930 AD. (Again, a similar explanation works for the tensed theorist, who'll replace all talk of hyperplanes ${ }_{\text {max }}$ with ersatzplanes etc.)

\subsection{Rippling history and the instability worry}

This sub-section considers how Wasserman's explanatory challenge nevertheless scuppers a variant of past vacillation theory. Uninterested readers may choose to skip ahead to $\S 4$.

According to the theory detailed in $\S \S 1-2$, when history changes it does so 'instantly'. As I step into the time machine in 2019 to kill Hitler in 1930, history is one way. Then, after the machine has been activated and I have slipped into the past, history is now a different way. That is: At time $t$ in 2019 history reflects one order of events (e.g. Hitler is alive in 1930, World War II has taken place, you stand watching me activate my time machine) whilst, at an instant later than $t$, history now reflects a different order (e.g. a time travelling assassin killing Hitler, World War II never taking place, and — quite probably — that you were never born and so no longer exist). We see this sort of 'instantaneous' change depicted in fictions like Agresti's The Lake House (2006) and Hoblit's Frequency (2000). 


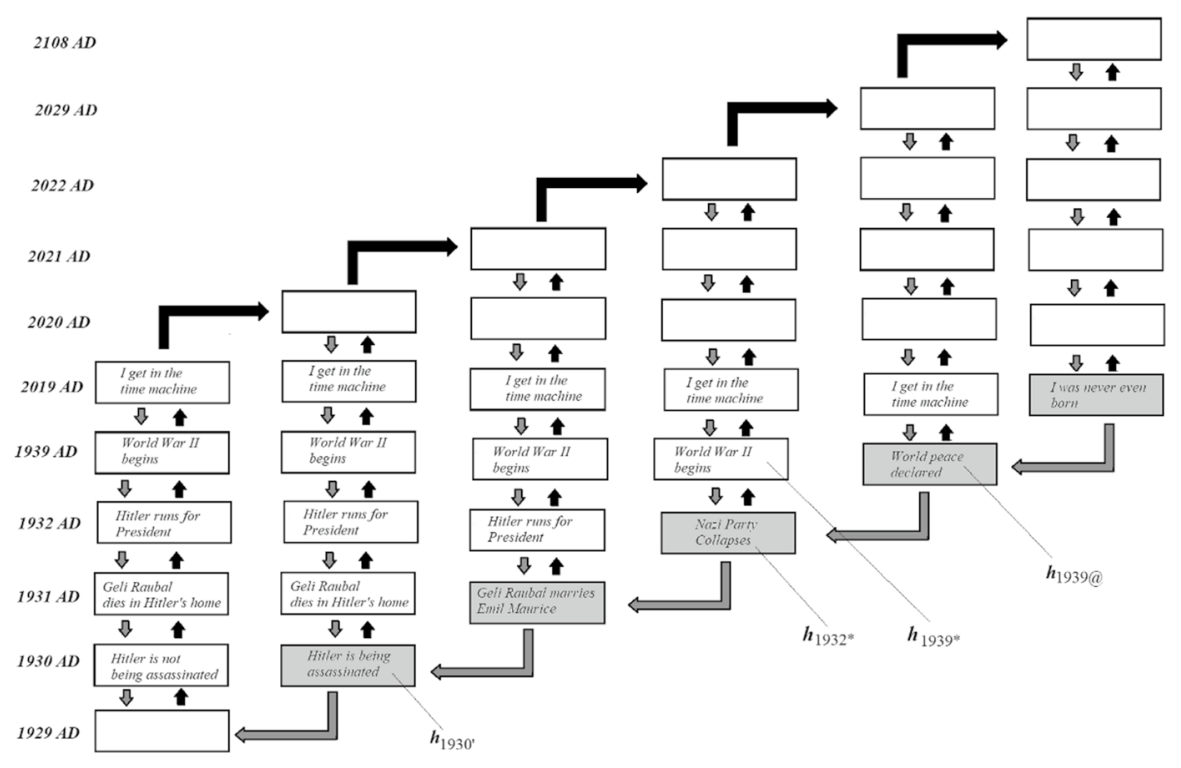

Fig. 4 Rippling past vacillation theory

But that isn't the only version of past vacillation theory we could consider. Both Goff (2010) and Meiland (1974: 162-64) discuss theories according to which the past changes over time, with the changes propagating through history as they 'ripple' out towards the present moment. Both Goff and Wasserman assume that history changes at the same rate that at which time flows. For example: If, in 2019, I go back in time to kill Hitler in 1930, it won't be until 2029 that World War II fails to come about in 1938. We also find this idea of 'rippling changes' in fiction, although for dramatic purposes it's more often assumed that the changes to history would move faster than one second per second such that people in the present might be 'wiped out' by changes made to the past (see Baxter's Timelike Infinity (1992), Robert J. Sawyer's 'On the Surface' (2003), and Mark Millar's Chrononauts (2015)). This sub-section explains why Wasserman-style explanatory worries threaten this alternative, 'rippling', version of past vacillation.

Figure 4 shows an arrangement of hyperplanes $\max _{\max }$ allowing for 'rippling' changes to history. For ease of presentation, I've assumed history changes at the rate of one second per second. The shaded hyperplanes $\max _{\text {represent those hyperplanes }}$ max $_{\text {m }}$ which are part of the 'new history' according to which I've killed Hitler in 1930. In normal spacetimes, if a hyperplane ${ }_{\max }$ is later than another hyperplane ${ }_{\max }$, what goes on at the former affects what happens at the latter. But given 'rippling', this fails

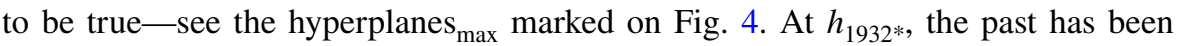
changed, Hitler is dead, and the Nazi party has collapsed. Whilst at $h_{1939^{*}}$-that is, at a hyperplane max $_{\operatorname{mat}}$ later than $h_{1932 *}$ - Hitler is still alive and well at the start of World War II. Something is 'blocking' the events of $h_{1932 *}$ from affecting $h_{1939 *}$. More problematically, that block later dissolves such that, a few years later, there's no block between $h_{1932 *}$ and $h_{1939 @}$. And it is at this stage that the explanatory problem 
crops up, for what explains the disparity between $h_{1932 *}$ being appropriately causally

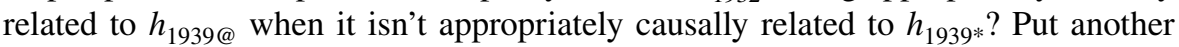
way: Given the time travel event that changes history takes place in $2020 \mathrm{AD}$, why do we have to wait until 2029 AD for the block to dissolve? That seems suitably similar to Wasserman's original worry and I can't see any principled answer that the past vacillation theorist can give. ${ }^{6}$

All of this is worth noting because 'non-rippling' past vacillation has an 'instability worry'. Imagine there is a doorway whereby anything passing through it travels back in time 90 years. Imagine I walk through it in 2020, hands outstretched. As the smartwatch on my wrist passes through the gate and arrives in the past, history changes. If a technological marvel like a twenty-first century smartwatch appeared in 1930, the future would be very different. Imagine that it results in a technologically accelerated World War II which ends with a world devastating nuclear war in the late 1940s. If the past changes instantaneously then, as soon as the watch travels back in time, the present moment becomes a nuclear wasteland. That means that I don't have the chance to follow my wristwatch through into the past. The present is 'unstable' in a way that makes time travel difficult.

Nor do the changes need to be so radical in order for such instability to arise. If I walked through the doorway, arms outstretched, then I'd equally have a problem if the changes in the past meant the future instantaneously changed so my arms were instead now passing through the time gate at a microscopically different angle. Even that small change would mean that the portion of my arm arriving in the past would be at a different angle to the part of my arm which had just passed through. Walking through the doorway would 'slice' me into pieces! Since even small changes to the past are likely to result in an alteration of at least such a magnitude, it's difficult to see how extended objects can travel through such portals given non-rippling past vacillation. ${ }^{7}$ If only changes to history took time to ripple forwards, a time traveller would have enough time to make their way through without being sliced to ribbons. But since rippling seems impossible, the only plausible version of past vacillation requires extended objects to 'teleport' if they are to travel through time (Effingham, 2020: $11-13)^{8}$

\footnotetext{
${ }^{6}$ Of course, there are unprincipled answers for there are all kinds of crazy gerrymandered possible worlds at which random things happen for no discernible reason. But whatever sense in which something is possible in virtue of such a world, it is a most unsatisfying sense.

7 This 'instability worry' is similar to the 'slicing problem' I develop in Effingham (2012).

8 There's also another problem with non-rippling past vacillation. In 2019 I travel to the 1930s to kill Hitler. Ten years after my arrival, in 1940, I will let exactly one of Bert and Ernie use my time machine, with an equal chance of it being either one of them. Given access to my time machine, both Bert and Ernie would do the same thing: Send a nuclear bomb to 1770 to kill Napoleon. That said, what happens when, in 2019, I use my time machine? It must be that, when I activate my time machine, all of history from 1770 onwards instantly changes such that a nuclear explosion occurs in France. The events of me arriving in 1930, killing Hitler, and giving my machine to one of Bert or Ernie, all go 'unrecorded by reality'. Further, there's no clear truthmaker for which of Bert or Ernie sent the bomb back to 1770. (This problem, which only arises given chancey events, strikes me as being connected to a similar problem about chance for future vacillation, detailed in $n 10$.)
} 


\section{Geachianism}

The future may vacillate as well as the past; FIXED FUTURE might be false instead of, or as well as, FIXED PAST. Cases of such vacillation are sometimes time travel cases e.g. stories in which there are prophecies or omens which are averted (Effingham, 2020: 12-13) or shows like Early Edition (1996-2000). In those cases, it's not hard to see how what has been said about time travel and past vacillation works similarly for such future vacillation.

But not every case of future vacillation will be a time travel case. In addition to time travel cases, there is at least one theory, which has nothing to do with time travel, requiring FIXED FUTURE to be false. This section discusses that theory.

\subsection{A Geachian open future}

Put crudely, open future theories say that future-tensed propositions have an alethic status different from that of past- and present-tensed propositions. For instance, they may be indeterminate, becoming true or false when the time they are about becomes present. Or they might all be false, but can become true when the time they are about becomes present. Or perhaps they lack truth values, later acquiring them when the time they are about becomes present. Geachian open future theory is in a similar vein, but says that propositions about the future can be non-trivially true or false, whilst having the odd alethic feature of being liable to change (Geach, 1977; Todd, 2011). For instance, imagine Malcolm smoked in 2010 and quit in 2015. In 2020 he says 'I was going to die young before I quit smoking.' A Geachian allows that this sentence can be literally true. For instance, it'd be true if, in 2010, Malcolm will die in 2025 of a smoking related disease, whilst in 2020 he instead will die peacefully in 2065. Clearly, such a theory needs the facts about the future to change as time passes i.e. it requires FIXED FUTURE to be false.

There are various reasons to accept Geachianism. It allegedly: better captures that our actions prevent bad outcomes; better responds to fatalist worries; better allows for interesting cases of foreknowledge; allows us to make better sense of progressives. Todd (2016) has a full discussion of these motivations. Here, I am uninterested in the motivations for Geachianism, instead being interested in how the metaphysical systems I've developed could be used to make sense of a Geachian world.

The metaphysical systems bearing out Geachianism are very similar to those developed in $\S \S 1-2$. Figure 5 a depicts a tenseless version consisting of a selection of hyperplanes $_{\max }$ bearing out Malcolm's avoidance of an early grave; Fig. 5b depicts the tensed version, replacing hyperplanes ${ }_{\max }$ with ersatzplanes. As in the case of past vacillation, all the work is being done by Ĺ/É CONVERSE (or its ersatz equivalent) being false. 


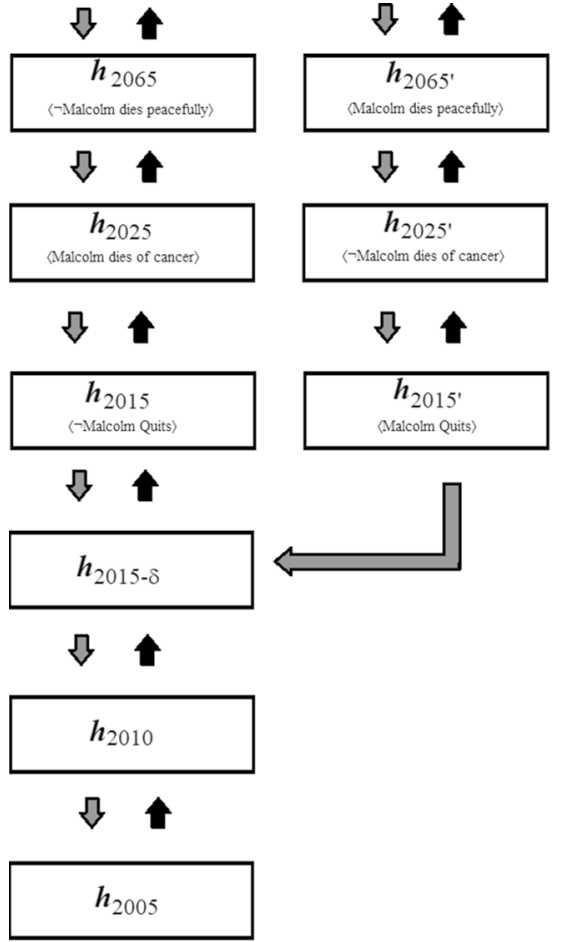

(a) Tenseless Future Vacillation
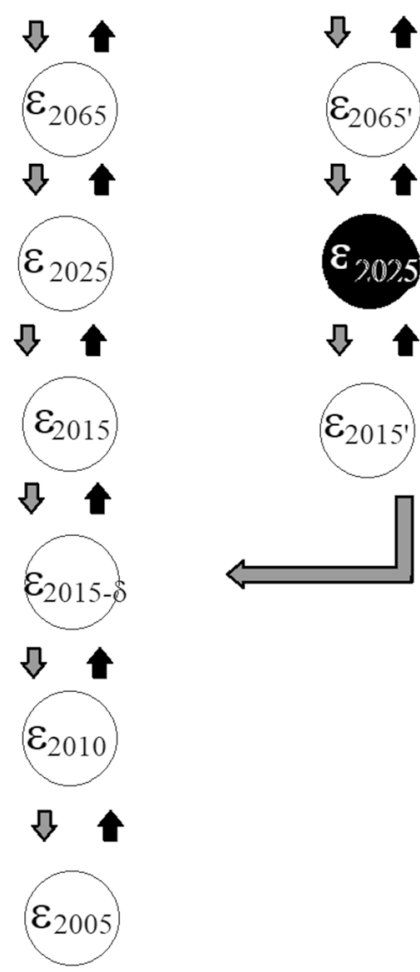

凤
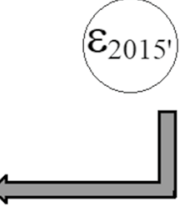

Fig. 5 Future vacillation Theory

(b) Tensed Future Vacillation

\subsection{Explanation and why we should favour the tensed version}

Wasserman's explanatory challenge can be applied to Geachianism. Say that $h_{2015^{\prime}}$ is the first hyperplane $\max _{\max }$ at which Malcolm is alive in 2025, whilst $h_{2015-\delta}$ is a hyperplane $_{\max }$ arbitrarily earlier than $h_{2015}$ (at which Malcolm is not alive in 2025). The future thus changes in $h_{2015}$, such that, at every prior hyperplane max $_{\max }$, Malcolm was going to die in 2025 whilst at every subsequent hyperplane max $_{\text {, }}$, he is now going to be alive in 2025 (See Fig. 5a). The challenge is explaining that change: why do all these 'extra' hyperplanes $\max$ exist (i.e. $h_{2015^{\prime}}, h_{2025}$ ', and $h_{2065}$ ') at which Malcolm chose to quit smoking? Why aren't there just the hyperplanes ${ }_{\max } h_{2015}, h_{2025}$, and $h_{2065}$ ? Why does time diverge at $h_{2015} ?^{?}$

\footnotetext{
${ }^{9}$ Distinguish this from the worry that it's prima facie contradictory that at $t_{1}$ I will $\phi$ at $t_{2}$ but, when $t_{2}$ comes about, I don't $\phi$. Todd (2011: 238-40) has already solved that problem: it's part-and-parcel of Geachianism being an open future theory that it's not odd that $\left\langle\right.$ At $t_{2}$ : Nikk $\left.\phi s\right\rangle$ has a 'funky' alethic status which is liable to change.
} 
There are four possibilities as to what the explanation might be: the explanation is either (i) something true of $h_{n \geq 2015}$ (or $h_{n^{\prime}>2015^{\prime}}$ ), for some value $n$; (ii) something true of $h_{n<2015-\delta}$, for some value $n$; (iii) something true of $h_{2015-\delta}$; or (iv) something true of $h_{2015^{\prime}}$.

Option (i) would make the explanation similar to that which the past vacillation theorist used in order to explain why history changes in time travel cases. But Geachianism has nothing to do with time travel. That said, to think time diverges because of something which goes on in the future is just plain weird for the Geachian to accept. For the Geachian, Malcolm's dying in 2065 rather than 2025 was the result of something which happened in 2015 or before, not after. Nor does option (ii) work since the same hyperplanes $\max$ prior to $h_{2015^{\prime}}$ are prior to $h_{2015-\delta}$. If one of them explained why Malcolm was alive in 2025, then at $h_{2015-\delta}$ Malcolm should also be alive in 2025, which is ex hypothesi false. Option (iii) won't work either. Whatever Malcolm does to change the future, the future changing should be simultaneous with that action. If Malcolm's choice to quit smoking is what causes him to be alive in 2025 then-simultaneous with that choice-he should be alive in 2025. Thus, if something taking place at $h_{2015-\delta}$ explained the change, Malcolm should be alive in 2025 at $h_{2015-\delta}$. Again, ex hypothesi that's false.

That leaves option (iv), according to which the explanation is to be found at $h_{2015^{\prime}}$. This is exactly what the Geachian should say explains the change in the future facts. Geachians will be libertarians about free will; it is Malcolm's libertarian choice which explains the relevant change. At $h_{2015-\delta}$, Malcolm wasn't going to choose to quit a moment later. A moment later, his libertarian free will trumps that and he does choose to quit. That choice is exercised at $h_{2015}$, and thus it's there that we find the appropriate explanation. (And the choice itself, being libertarian, has no metaphysical explanation (Gale \& Pruss, 1999: 470), hence why there's no need to explain how $h_{2015}$ and $h_{2015^{\prime}}$ both have the same pasts and yet differ.)

But with this explanation comes the end of the road for the tenseless theory since

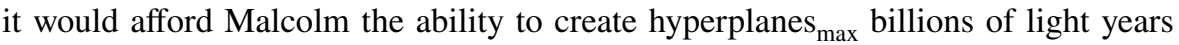
wide, as well as populate them with galaxies and planets and people. To understand why, we must first pad out the Geachian theory and explain why it's true in 2010 that, in 2015, Malcolm will choose to keep smoking. My presumption is that Geachians say that the future truths are those which are currently most likely to come about. Because it's most likely that Malcolm freely chooses to keep smoking in 2015, it's true in 2010 that he will keep smoking in 2015. More generally, where (i) ' $\mathrm{Ch}_{n}$ ' is the objective chance function (outputting the objective chance of the inputting proposition occurring $n$ years in the future) and (ii) $\psi_{1}, \psi_{2} \ldots$ are mutually exclusive propositions exhaustively describing the world (such that $\Sigma_{m} \mathrm{Ch}_{n}\left(\psi_{m}\right)=1$ ):

$\left[\mathrm{WILL}_{n}: \varphi\right] \leftrightarrow$ for some value $j$ and all distinct values $k$ : (i) $\mathrm{Ch}_{n}\left(\psi_{j}\right)>\mathrm{Ch}_{n}\left(\psi_{k}\right)$ and (ii) $\psi_{j}$ entails $\varphi .^{10}$

\footnotetext{
10 Two notes. One: This will need finessing to account for cases where conflicting outcomes are equally likely. Indeed, equally likely outcomes might end up being an insuperable problem for Geachianism ( $c f$ $n 8$ ). Two: It must be possible for libertarian choices to have objective chances of coming about, which sounds problematic to me.
} 


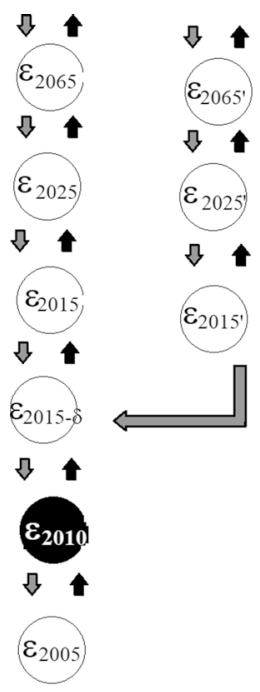

(a) Static Ersatz Relations

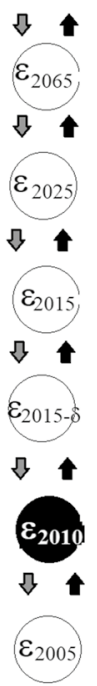

(Left: Relations when 2010 is present; Right: Relations when 2025 is present)

Fig. 6 Dynamic and static Eratz Relations

So the future vacillates only when an agent chooses something that was not previously their most likely choice. In Malcolm's case, $h_{2010}$ and $h_{2011}$ are both hyperplanes $_{\max }$ at which he chose the most likely course of action of not quitting smoking. So in those cases, Malcolm's choices don't create any hyperplanes ${ }_{\text {max }}$. But in 2015, when Malcolm chooses something not most likely, that choice does cause there to be additional hyperplanes ${ }_{\max }$, i.e. $h_{2025}, h_{2065}$ etc. And this is utterly bizarre! That Malcolm's choices have the incredible casual power to bring hyperplanes ${ }_{\max }$ (and their contents!) into existence is a power reserved for gods, not Nicorette!

The tensed view is more plausible. Ersatzplanes are propositions; being propositions, and unlike hyperplanes ${ }_{\max }$, they exist regardless of Malcolm's choice to quit. On the tenseless view, if Malcolm didn't choose to quit, $h_{2015^{\prime}}$ wouldn't have existed. But, on the tensed view, the corresponding ersatzplane would still have existed for (by necessity) there is a proposition which has as conjuncts all and only those intrinsic propositions that would have been true about $h_{2015^{\prime}}$. So, on the tensed view, Malcolm's choices don't have the crazy existential powers which they would have had on the tenseless view. Instead, his choices have power over whether some proposition is $L_{\varepsilon}$-related to some other proposition. And that's a reasonable power to have given that, according to regular ersatz presentism, agents have that power anyhow. For instance, the regular ersatz presentist will say that my choice to visit my friends tomorrow explains why $\langle\mathrm{Nikk}$ is visiting his friend $\rangle$ is a conjunct of a proposition $\dot{L}_{\varepsilon}$-related to the presently true ersatzplane. 


\subsection{Static vs. dynamic ersatz relations}

Thus far, the tensed vacillation theory I've sketched has it that the $E_{\varepsilon^{-}}$and $L_{\varepsilon^{-}}$ relations between the ersatzplanes hold tenselessly, never changing. The Geachian should deny this. Imagine it's presently 2010. Figure 6a depicts the structure of ersatzplanes that there would be were $E_{\varepsilon}-/ L_{\varepsilon}$-relations to be changeless. Something must explain why the ersatzplanes have that structure e.g. something must explain why an ersatzplane at which Malcolm won't quit in the future (i.e. $\varepsilon_{2010}$ ) is earlier than one at which he does (i.e. $\varepsilon_{2015}$ ). Malcolm's past and present choices cannot explain that structure for, as of 2010, he has done nothing that means he'll quit in 2015. And if 2010 is present, it cannot be explained by his future choices either for, in 2010, his future choice is to carry on smoking!

(If we really wanted the $E_{\varepsilon}-/ L_{\varepsilon}$-relations to never change, I suspect the only option would be to introduce the mirror image of $§ 2.2$ 's WAS operator, the WILL operator. In that case, there'd be a difference between what will happen and what will really happen. The ersatzplane structure would then be explained by (in 2010) it being true that Malcolm will choose to smoke but (in 2010) it being true that Malcolm will really quit. But this is problematic in two ways. First: Fig. 6a allows for an open future, but not a really open future. This undermines the spirit, if not the letter, of the idea that libertarian free will requires an open future. Second: In §2.2 I analysed the WAS operator in terms of $E_{\varepsilon}$ - and $L_{\varepsilon}$-relations between ersatzplanes. We cannot here do the same for the WILL operator for then we'd be explaining the structure of $E_{\varepsilon}$ - and $L_{\varepsilon}$-relations between ersatzplanes in terms of facts of the form 'WILL $\varphi$ ' (i.e. facts about what really will happen) which are, in turn, explained by that structure. We'd have a circular explanation! The Geachian would instead have to take the WILL operator to be a primitive. That's a significant ideological burden (and also starts to make the theory sound more like the hypertemporal theory of $\$ 1.3$ with its two operators, WILL and HWILL). So set aside this 'static' model).

Instead, the Geachian should accept a 'dynamic' picture of the tenseless relations. In 2010, $\varepsilon_{2010}$ is presently true. Moreover $\varepsilon_{2015^{\prime}}$ (according to which Malcolm quits smoking in 2015) isn't $L_{\varepsilon}$-related to $\varepsilon_{2010}$-indeed it doesn't stand in any $E_{\varepsilon^{-}}$ $/ L_{\varepsilon}$-relations whatsoever. In 2015, Malcolm chooses to quit. Simultaneous with that, the $E_{\varepsilon}$ - and $L_{\varepsilon}$-relations alter. Not only does $\varepsilon_{2015}$, become true but it is also now $L_{\varepsilon}$-related to $\varepsilon_{2010}$. See Fig. 6b. Thus changeable ersatz tenseless relations solve the problem.

\section{Conclusion}

This paper has introduced a way of understanding how facts about what did (or will) happen can change over time. In the case of changing what was once the case, this allows for new models of time travel. Those models have both tensed and tenseless versions. Further, there is a Geachian theory of the open future which allows what will be the case to change. In that case, it is most natural to favour the tensed version alone. 
Acknowledgements Many thanks to the Departments of Philosophy at the University of Birmingham and the University of Manchester, who gave feedback on earlier incarnations of this paper. Thanks also to the anonymous referees, both of this paper and drafts of my book in which this material earlier appeared.

Open Access This article is licensed under a Creative Commons Attribution 4.0 International License, which permits use, sharing, adaptation, distribution and reproduction in any medium or format, as long as you give appropriate credit to the original author(s) and the source, provide a link to the Creative Commons licence, and indicate if changes were made. The images or other third party material in this article are included in the article's Creative Commons licence, unless indicated otherwise in a credit line to the material. If material is not included in the article's Creative Commons licence and your intended use is not permitted by statutory regulation or exceeds the permitted use, you will need to obtain permission directly from the copyright holder. To view a copy of this licence, visit http://creativecommons.org/licen ses/by/4.0/.

\section{References}

Baxter, S. (1992). Timelike Infinity. HarperCollins.

Bourne, C. (2006). A Future for Presentism. OUP.

Cameron, R. (2011). Truthmaking for Presentists. Oxford Studies in Metaphysics, 6, 55-100.

Cameron, R. (2013). Changing Truthmakers: Reply to Tallant and Ingram. Oxford Studies in Metaphysics, 8, 362-373.

Chrononauts. (2015). [Comic series] Created by Mark Millar and Sean Gordon Murphy. Image Comics.

Early Edition. 1996-2000. [Tv series] Created by Ian Abrams, Patrick Page, and Vik Rubenfeld. USA: CBS.

Effingham, N. (2012). An Unwelcome Consequence of the Multiverse Thesis. Synthese, 184, 375-386.

Effingham, N. (2020). Time Travel: Probability and Impossibility. OUP.

Fine, K. (2001). The Question of Realism. Philosopher's Imprint, 1, 1-30.

Frequency. (2000). [Film] Directed by Gregory Hoblit. New Line Cinema.

Gale, R., \& Pruss, A. (1999). A New Cosmological Argument. Religious Studies, 35, 461-476.

Geach, P. (1977). Providence and Evil. Cambridge University Press.

Goddu, G. (2003). Time travel and Changing the Past (Or How To Kill Yourself and Live to Tell the Tale). Ratio, 16, 16-32.

Goff, P. 2010. Could the Daleks Have Stopped the Pyramids Being Built?, in Lewis and Smithka (eds.) Doctor Who and Philosophy. Open Court.

Hales, S. (2010). No Time Travel for Presentists. Logos \& Episteme, 2, 353-360.

Hales, S. (2011). Reply to Licon on Time Travel. Logos \& Episteme, 4, 633-636.

Keller, S., \& Nelson, M. (2001). Presentists should believe in time travel. Australasian Journal of Philosophy, 79, 333-345.

Markosian, N. (2004). A Defence of Presentism. Oxford Studies in Metaphysics, 1, 47-82.

Markosian, N. (2020). The Dynamic Theory of Time and Time Travel to the Past. Disputatio, 12, $137-165$.

Meiland, J. (1974). A Two-Dimensional Passage Model of Time for Time Travel. Philosophical Studies, 26, 153-173.

Sawyer, R. 2003. On the Surface, in Martin Greenberg and Larry Segriff (eds.) Future Wars. DAW.

Skow, B. (2015). Objective Becoming. OUP.

Tallant, J. (2018). Truth and the World: An Explanationist Theory. Routledge.

Tallant, J., \& Ingram, D. (2012). Presentism and Distributional Properties. Oxford Studies in Metaphysics, 7, 305-314.

The Lake House. (2006). [Film] Directed by Alejandro Agretsi. Warner Bros. Pictures.

Todd, P. (2011). Geachianism, Oxford Studies in Philosophy of. Religion, 3, 222-251.

Todd, P. (2016). On behalf of a mutable future. Synthese, 193, 2077-2095.

van Inwagen, P. (2010). Changing the Past. Oxford Studies in Metaphysics, 5, 3-28.

Wasserman, R. (2018). Paradoxes of Time Travel. OUP.

Publisher's Note Springer Nature remains neutral with regard to jurisdictional claims in published maps and institutional affiliations. 